\title{
The Anthelmintics Activity of Ethanol Extract of African Leaf (Vernonia amygdalina) on Mortality of Fasciola gigantica In Vitro
}

\section{Aktivitas Anthelmintika Ekstrak Etanol Daun Afrika (Vernonia amygdalina) Terhadap Mortalitas Fasciola gigantica Secara In Vitro}

\author{
${ }^{1)}$ Dhio Asmaydo, 2) Iwan Sahrial Hamid, 3)Mchammad Yunus, 3) Kusnoto, ${ }^{2)}$ Muhammad \\ Sukmanadi, ${ }^{3)}$ Endang Suprihati \\ 1) Student, Faculty of Veterinary Medicine, Universitas Airlangga \\ ${ }^{2}$ Department of Basic Veterinary Medicine, Faculty of Veterinary Medicine, Universitas Airlangga \\ 3) Department of Veterinary Parasitology, Faculty of Veterinary Medicine, Universitas Airlangga.
}

Received : 20-02-2019, Accepted : 10-03-2019, Published : 19-03-2019

\begin{abstract}
The Aims of this study is to know the anthelmintics activity of ethanol extract of african leaf (Vernonia amygdalina) on mortality of Fasciola gigantica in vitro. Method that used in the research was a completely randomized design. There were five treatments and each treatment was done in four replications. This research used ten Fasciola gigantica in each treatment for all replications. The observation and recording of dead Fasciola gigantica was done at 2, 4, 6, 8, and 10 hours. Fasciola gigantica were declared dead if there was no movement when disturbed by anatomy tweezers and when dipped in slightly warm water $\left(50^{\circ} \mathrm{C}\right)$. The obtained data was analyzed using ANOVA and continued with Duncan Multiple Range Test. The result of this research show that ethanol of extract of African Leaf (Vernonia amygdalina) has activity anthelmintic on mortality of Fasciola gigantica in vitro. Ethanol extract african leaf (Vernonia amygdalina) with concentration of $1.4 \%$ is the optimal concentration of anthelmintics. This higher the concentration of the extract, the higher the property of anthelmintics.
\end{abstract}

Keywords: Vernonia amygdalina, anthelmintic, Fasciola gigantica

\section{Pendahuluan}

Perendaman Fasciola gigantica menggunakan ekstrak etanol daun Afrika (Vernonia amygdalina) belum banyak diteliti. Parasit yang digunakan dalam penelitian ini adalah Fasciola gigantica. Parasit ini merupakan subjek yang merugikan pada stadium dewasa sehingga peneliti ingin mengetahui apakah terdapat aktivitas anthelmintika ekstrak etanol daun Afrika (Vernonia amygdalina) terhadap mortalitas Fasciola gigantica secara in vitro.

Endoparasit fasciolosis cukup menimbulkan masalah dalam bidang peternakan yang disebabkan oleh cacing hati ini, hewan ternak yang dapat terinfeksi oleh cacing hati ini antara lain sapi, kerbau, kambing dan domba. Kerugian ekonomi akibat fasciolosis di Indonesia akibat pembua-ngan organ hati sapi yang terinfeksi Fasciola gigantica mencapai 28,28 miliar rupiah (Budiono, dkk 2018).

Secara umum patogenesis dan gejala klinis fasciolosis tergantung dari jumlah dan tahap perkembangan cacing di hepar serta tingkat kerusakan pada organ hepar. Kejadian infeksi dimulai dari masuknya metaserkaria ke dalam tubuh inang definitif melalui makanan atau minuman yang terkontaminasi, kemudian metaserkaria masuk ke dalam usus terus menembus mukosa usus dan masuk ke rongga abdomen dan bermigrasi menuju hepar. Akibat yang ditimbulkan oleh cacing dewasa ini yaitu rusaknya jaringan organ hepar, rusaknya parenkim hati hingga mengakibatkan perdarahan, dan rusaknya epitel saluran empedu sehingga terbentuknya cirrhosis hepatitis.

Penggunaan anthelmintika adalah efektif untuk pengobatan fasciolosis, namun obat yang beredar adalah obat sintetik yang mempunyai berbagai masalah karena anthelmintika tersebut memiliki toksisitas, apabila produk yang berasal dari ternak ini dikonsumsi oleh manusia dapat menimbulkan ancaman serius bagi kesehatan manusia (Adate et al., 2012). Penelitian saat ini banyak yang memanfaatkan tanaman obat herbal, yang memiliki tujuan untuk menguji efek dalam mencegah dan mengatasi penyakit infeksi yang disebabkan oleh cacing. Daun Afrika (Vernonia 
amygdalina) merupakan salah satu tanaman yang bermanfaat sebagai tanaman obat. Vernonia amygdalina adalah tumbuhan semak yang berasal dari benua Afrika dan bagian lain dari Afrika, seperti Nigeria, Kamerun, dan Zimbabwe dan negara beriklim tropis lainnya.

Senyawa yang berperan sebagai aktivitas anthelmintika adalah saponin, tannin, dan flavonoid. Menurut Munthe (2011), saponin bekerja dengan cara menghambat kerja enzim kolinesterase. Enzim ini berperan menjaga agar otot, kelenjar, dan syaraf dalam tubuh dapat bekerja teratur apabila enzim kolinesterase tidak dapat melaksanakan tugasnya dalam tubuh maka otot cacing akan berkontrasi terus-menerus tanpa dapat dikendalikan. Hal ini menyebabkan penumpukan asetilkolin sehingga otot cacing mengalami hiperkontraksi dan menyebabkan kematian pada cacing (Kuntari, 2008). Senyawa tannin menpunyai daya anthelmintika dengan cara menganggu pembentukan energi dengan menghambat fosforilasi oksidatif (Salhan et al., 2011). Senyawa flavonoid mempunyai daya anthelmintika dengan cara menganggu impuls saraf dan keseimbangan cacing sehingga mengalami paralisa dan akhirnya mati (Fitriana, 2008).

\section{Materi dan Metode Penelitian}

Tahap Pembuatan Ekstrak Daun Afrika (Vernonia amygdalina)

Pembuatan ekstrak daun Afrika (Vernonia amygdalina) dilakukan di Fakultas Kedokteran Hewan, Universitas Airlangga. Metode yang di gunakan adalah teknik ekstrak maserasi dengan menggunakan pelarut etanol teknis $96 \%$ sehingga akan didapat ekstrak dalam bentuk padat yang dapat ditimbang.

Pembuatan ekstrak daun Afrika dilakukan di Laboratorium Farmakologi Veteriner, Fakultas Kedokteran Hewan, Universitas Airlangga. Daun Afrika sebanyak 5000 gr dicuci bersih, dipotong kemudian dikeringkan dengan cara diangin-anginkan terlindung dari sinar matahari langsung. Setelah kering daun dihaluskan kemudian diayak hingga diperoleh bentukan simplisia halus. Serbuk daun Afrika dimaserasi dengan cara ditambahkan pelarut etanol $96 \%$ dan didiamkan selama 24 jam setelah itu disaring. Residu dimaserasi ulang sebanyak tiga kali. Filtrat yang terkumpul kemudian diuapkan menggunakan rotavapor dengan water bath bersuhu $5^{\circ} \mathrm{C}$, kecepatan 70 rpm, dan tekanan o,7 bar sehingga diperoleh ekstrak kental daun afrika yang siap digunakan. Ekstrak yang dihasilkan disimpan pada suhu $4^{\circ} \mathrm{C}$ hingga digunakan (Bachaya et al., 2009; Mahardika et al., 2017; Qurrota, 2016).

\section{Tahap Perlakuan}

Penelitian ini menggunakan 5 perlakuan dengan masing - masing 4 ulangan yaitu $\mathrm{Po}, \mathrm{Pl}$, $\mathrm{P}_{2}, \mathrm{P}_{3}$ dan $\mathrm{P}_{4}$. Po adalah kelompok kendali negatif, cacing direndam dengan laruta $\mathrm{NaCl}$ fisiologis, P1 adalah kelompok kendali positif, cacing direndam dengan larutan Nitroxynil $\mathbf{2} \%$, $\mathrm{P} 2$ adalah kelompok perlakuan cacing yang direndam dengan ekstrak etanol daun Afrika konsentrasi $0,35 \%, \quad \mathrm{P}_{3}$ adalah kelompok perlakuan cacing yang direndam dengan ekstrak etanol daun Afrika konsentrasi o,7\%, $\mathrm{P}_{4}$ adalah kelompok perlakuan perlakuan cacing yang direndam dengan ekstrak etanol daun Afrika konsentrasi 1,4\%.

\section{Analisis Data}

Data yang diperoleh dari hasil perhitungan berupa jumlah kematian Fasciola gigantica kemudian dianalisis menggunakan ANOVA dan untuk membandingkan efektifitas antar perlakuan dilakukan Uji Jarak Berganda Duncan menggunakan bantuan Statistical Product and Service Solution.

\section{Hasil dan Pembahasan}

Hasil penelitian yang telah dilakukan dalam lima perlakuan perendaman dengan empat kali pengulangan yaitu perendaman dalam larutan $\mathrm{NaCl}$ fisiologis (Po), perendaman dalam larutan nitroxynil 2\% ( $\left.\mathrm{P}_{1}\right)$, Perendaman dalam ekstrak etanol daun Afrika o,35\% ( $\left.\mathrm{P}_{2}\right)$, $0,7 \% \quad\left(\mathrm{P}_{3}\right), \quad 1,4 \% \quad\left(\mathrm{P}_{4}\right), \quad$ didapatkan hasil kumulatif kematian cacing tertinggi pada konsentrasi $\quad 1,4 \% \quad\left(\mathrm{P}_{4}\right)$. Mekanisme kerja nitroxynil yaitu menghambat fosforilasi oksidatif pada mitokondria cacing, pada keadaan tersebut dapat menganggu produksi ATP yang merupakan sumber energi cacing, apabila kekurangan energi maka cacing akan mati (Rahman et al., 2017). Untuk menentukan kriteria keadaan cacing yang mati atau masih hidup setelah diinkubasi dengan cara diusik dengan menggunakan batang pengaduk kaca. Apabila cacing diam, segera ambil dengan menggunakan pinset anatomis dan masukkan bagian ekor cacing ke dalam air hangat bersuhu $5^{\circ} \mathrm{C}$. Cacing yang bergerak menandakan bahwa cacing mengalami paralisis, sedangkan cacing yang diam menunjukkan bahwal telah mengalami kematian (Ali et al., 2012). Cacing yang mengalami paralisa dikembalikan ke dalam cawan perlakuan hingga cacing meng- 
alami kematian. Berdasarkan hasil penelitian tersebut didapatkan persentase kematian Fasciola gigantica pada semua per lakuan dalam waktu pengamatan 2, 4, 6, 8, dan 10 jam setelah perlakuan adalah seperti yang tertera pada Gambar 1.

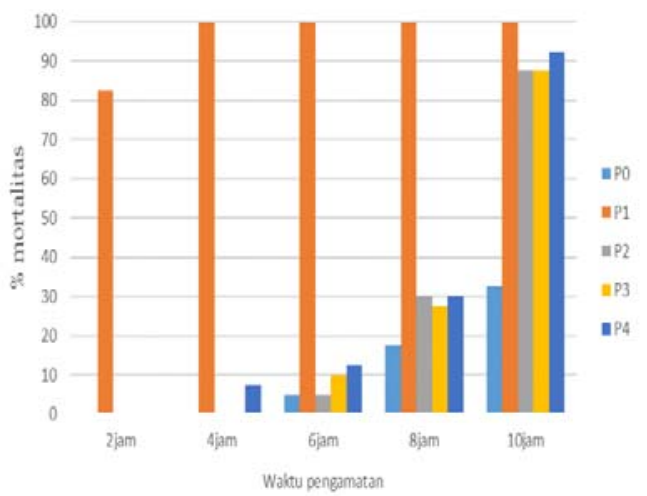

Gambar 1 Mortalitas Fasciola gigantica tiap perlakuan

Dari Gambar 1 menunjukkan bahwa kematian Fasciola gigantica pada perlakuan perendaman dengan ekstrak etanol daun Afrika konsentrasi 1,4\% memiliki kemampuan lebih cepat dari ekstrak etanol daun afrika pada konsentrasi $0,35,0,7 \%$ dan $\mathrm{NaCl}$ fisiologis, namun belum dapat menyamai efikasi dari nitroxynil 2\%. Pada konsentrasi $1,4 \%$ ini didapatkan kematian paling tinggi.

Hasil analisis statistika pengamatan pada 2 jam dapat diketahui denga ekstrak etanol daun Afrika belum menunjukkan aktivitas anthelmintika karena belum didapat kematian dari berbagai konsentrasi ekstrak yang dilakukan. Menurut Shargel \& Yu (1988), obat memerlukan waktu untuk mencapai sasaran organ yang dituju dan untuk melewati membran sel cacing, selain itu faktor yang mempengaruhi lama reaksi obat atau zat aktif adalah kemampuannya melewati membran sel cacing. Obat atau zat kimia yang larut dalam lemak lebih mudah melewati membran sel daripada obat atau zat kimia yang larut dalam air. Saponin dan tannin merupakan senyawa metabolit sekunder yang dapat larut dalam air maupun etanol (Henry, 1949), sehingga memerlukan waktu yang lebih lama untuk dapat melewati membran sel dan membawa pengaruh terhadap sel dan organ sasaran.

Hasil analisis statistika pengamatan pada 4 jam diketahui sudah menunjukkan bahwa ekstrak etanol daun Afrika memiliki aktivitas anthelmintika karena pada perlakuan yang diberikan pada konsentrasi 1,4\% menunjukkan adanya kematian yang berarti onset of action mulai bekerja pada 4 jam dibandingkan dengan kelompok perlakuan EDA lainnya.

Hasil analisis statistika pengamatan pada 6 jam diketahui sudah menunjukkan peningkatan aktivitas anthelmintika pada semua kelompok perlakuan dengan menunjukkan hasil kematian yang berbeda-beda. Kemampuan ekstrak etanol daun Afrika untuk membunuh Fasciola gigantica karena adanya bahan aktif yang terkandung di dalamnya. Bahan aktif tersebut yaitu saponin, tannin, dan flavonoid. Menurut Munthe (2011), saponin bekerja dengan cara menghambat kerja enzim kolinesterase. Enzim ini berperan menjaga agar otot, kelenjar, dan syaraf dalam tubuh dapat bekerja teratur apabila enzim kolinesterase tidak dapat melaksanakan tugasnya dalam tubuh maka otot cacing akan berkontrasi terus-menerus tanpa dapat dikendalikan. Hal ini menyebabkan penumpukan asetilkolin sehingga otot cacing mengalami hiperkontraksi dan menyebabkan kematian pada cacing (Kuntari, 2008). Senyawa tannin menpunyai daya anthelmintika dengan cara menganggu pembentukan energi dengan menghambat fosforilasi oksidatif (Salhan et al., 2011). Senyawa flavonoid mempunyai daya anthelmintika dengan cara menganggu impuls saraf dan keseimbangan cacing sehingga mengalami paralisa dan akhirnya mati (Fitriana, 2008).

Hasil analisis statistika pengamatan pada 8 jam diketahui menunjukkan kematian yang merata antar kelompok perlakuan ekstrak. Mortalitas Fasciola gigantica dari kelompok perlakuan menunjukkan berbeda nyata pada jam ke delapan. Setiap perlakuan menunjukkan jumlah kematian diatas kendali negatif.

Hasil analisis statistika pengamatan pada 10 jam diketahui pada konsentrasi 1,4\% menunjukkan angka kematian tertinggi dibandingkan kelompok perlakuan EDA lainnya. Hasil tersebut sesuai dengan yang dinyatakan oleh Berijaya \& Tetriana (1999) bahwa semakin tinggi konsen-trasi yang digunakan maka semakin cepat dan efektif dalam membunuh Fasciola gigantica. Hal ini dikarenakan cacing akan menyerap lebih banyak saponin dan tannin yang dapat menjadi racun pada tubuh cacing hingga dapat menye-babkan kematian pada Fasciola gigantica. 


\section{Kesimpulan}

Berdasarkan hasil penelitian tersebut maka dapat ditarik kesimpulan bahwa ekstrak etanol daun Afrika (Vernonia amygdalina) pada konsentrasi $1,4 \%$ memiliki aktivitas anthelmintika paling cepat terhadap mortalitas Fasciola gigantica secara in vitro.

\section{Daftar Pustaka}

Adate, P.S., S. Parmesawaran and Y. Chauhan. 2012. In Vitro Anthelmintic Activity of Stem Extracts of Piper betle Linn against Pheretima Posthuma. Pharmacognosy Journal, 4(29), 61-65.

Bachaya, H.A., Z. Iqbal, M.N. Khan, and A. Jabbar. 2009. Anthelmintic activity of Ziziphus nummularia (bark) and Acacia nilotica (fruit) against Trichostrongylid nematodes of sheep. Journal of ethnopharmacology, 123(2), 325-329.

Berijaya dan Tetriana. 1999. Pengaruh perasan dan ekstrak buah mengkudu (Morinda citrifolia) secara in-vitro. Prosiding I Seminar HasilHasil Penelitian Bidang Ilmu Hayat .PAU Ilmu Hayat IPB 16 September 1999.

Budiono, N.G., F. Satrija, Y. Ridwan, dan D. Nur. 2018. Trematodosis pada Sapi dan Kerbau di Wilayah Endemik Schistosomiasis di Provinsi Sulawesi Tengah, Indonesia. Jurnal Ilmu Pertanian Indonesia, 23(2), 112-126.

Fitriana, S. 20o8. Penapisan Fitokimia dan Uji Aktivitas Anthelmintik Ekstrak Daun Jarak (Jatropha curcas L.) Terhadap cacing Ascaridia galli Secara in vitro [Skripsi]. Fakultas Peternakan. Institut Pertanian Bogor.
Henry, T.A. 1949. The Plant Alkaloids. Fourth Edition. Philadelphia: The Blakiston Company.

Kuntari, T. 20o8. Daya Antihelmintik air rebusan daun ketepeng (Cassia alata L.) terhadap cacing tambang anjing in vitro. Jurnal Logika, 5(1).

Mahardika, M.M., S.A. Sudjarwo, and S. Koesdarto. 2017. Anthelmintic Activity of Ocimum sanctum Linn. Leaves Ethanol Extract Against Fasciola gigantica in vitro. KnE Life Sciences, 3(6), 266-277.

Munthe, S.A. 2011. Pengaruh Binaan LSM Terhadap Perilaku dan Kadar Cholinesterase Pada Petani Di Kecamatan Kabanjahe Tanah Karo. [Tesis]. Fakultas Kesehatan Masyarakat. Universitas Sumatera Utara.

Qurrota, A. 2016. Uji Efektifitas Daya Anthelmintik Ekstrak Daun Kelor (Moringa oleifera) Terhadap Mortalitas Cacing Heterakis gallinarum Secara InVitro (Doctoral Dissertation, UNIVERSITAS AIRLANGGA).

Salhan, M., B. Kumar, P. Tiwari, P. Sharma, H. Kaur, and M. Gautam. 2011. Comparative Anthelmintic Activity of Aqueous and Ethanolic Leaf Extracts of Clitoria Ternatea. International Journal of Drug Development and Research, 3(1), 68-69.

Shargel, L. dan A.B. Yu. 1988. Biofarmasetika dan farmakokinetika terapan. Terjemahan) Dr. Fasich, Apt dan Dra. Siti Sjamsiah, Apt. Surabaya: Airlangga University Press, 175. 